\title{
PENGARUH HARGA DAN KUALITAS PELAYANAN TERHADAP LOYALITAS MELALUI KEPUASAN WISATAWAN NUSANTARA PADA MASKAPAI LION AIR DI BALI
}

\author{
Christian Hamonangan Sinaga \\ I Nyoman Sudiarta \\ I GPB. Sasrawan Mananda \\ Email : christian.h.sinaga@gmail.com \\ PS.S1 Industri Perjalanan Wisata \\ Fakultas Pariwisata UNUD
}

\section{ABSTRACT}

This research has purposed to find out the influence of price, service quality, loyalty and mediates satisfaction in correlation to price and loyalty to domestic tourist satisfaction at Lion Air Company Bali. The research used thepurposive sampling approach to 70 respondents of the Lion Air in Bali. Location of this research is at Domestic departure terminal of Ngurah Rai International Airport Tuban - Bali. The research was using two variables, those are the independent variable $(X)$, and the dependent variable (Y). The analysis method used are the validity and instrument reliability test, normality test, and path analysis test.

Based on result analysis, indicators in this research are valid and reliable. There is a positive and significant influence between the price to satisfaction of local tourists at Lion Air airline in Bali, there is positive and significant influence between service quality to satisfaction of local tourists at Lion Air company in Bali. There is positive and significant influence between satisfaction to the loyalty of local tourists at Lion Air airline in Bali. There is positive and significant influence between the price to the loyalty of local tourists at Lion Air airline in Bali. There is positive and significant influence between service quality to the loyalty of local tourists at Lion Air airline in Bali. Therefore future research is necessary to conduct further research using other variables suspected to affect the loyalty rating.

Keywords : Price, Service Quality, Loyalty, Satisfaction.

\section{PENDAHULUAN}

Dalam kepariwisataan Indonesia, Bali menjadi salah satu pulau yang diunggulkan. Bali merupakan salah satu pulau kecil yang memiliki potensi sangat besar dalam bidang pariwisata. Bali sebagai daerah tujuan wisata telah banyak dikunjungi oleh wisatawan mancanegara dan nusantara. Perkembangan pariwisata Bali yang sangat pesat, dimana rata-rata pertumbuhan kunjungan wisatawan nusantara ke Bali dalam enam tahun terakhir yaitu 2010 - 2015 mengalami fluktuasi. Total jumlah kunjungan
Wisatawan Nusantara ke Bali dari 2010-2015 sebanyak 36.905.965 dengan rata-rata 6.150.994. Peningkatan kunjungan wisatawan tersebut merupakan fakta bahwa Bali masih menarik dan layak untuk dikunjungi sebagai salah satu daerah tujuan wisata.

International Air Transport Association (IATA) memperkirakan, selama periode 2010 2014 laju pertumbuhan penerbangan dalam negeri bisa mencapai $10 \%$ per tahun. Berkembangnya industri penerbangan sangat membantu wisatawan untuk melakukan kunjungan wisata keberbagai tempat yang ingin dituju. Karena industri penerbangan merupakan 
bagian yang tidak dapat dipisahkan dengan sistem kepariwisataan.

Lion Air merupakan salah satu perusahaan yang memberikan jasa angkutan udara. Seperti halnya perusahaan-perusahaan penerbangan lainnya Lion Air ikut dalam bersaing untuk memberikan pelayanan yang terbaik kepada penumpang. Persaingan yang ketat ini mendorong tumbuh suburnya kiat-kiat kreatif manajemen jasa penerbangan. Memberikan harga yang relatif murah dalam menjual produk menjadi salah satu cara untuk menarik daya beli konsumen. Selain harga yang relatif murah, Lion Air juga berusaha memberikan pelayanan yang baik terhadap konsumen. Untuk itu ingin diketahui pengaruh harga, kualitas pelayanan, dan kepuasan terhadap loyalitas wisatawan nusantara pada maskapai Lion Air di Bali.

\section{METODE PENELITIAN}

Pengambilan data dilakukan di terminal keberangkatan Domestik Bandara International Ngurah Rai Tuban - Bali. Penentuan lokasi ini karena pada terminal domestik tempat berkumpul wisatawan. Sehingga wisatawan dapat mengisi kuesioner dengan baik. Dalam penulisan ini menggunakan dua jenis variabel yaitu variabel independent $(X)$ dan variabel dependent (Y). Variabel independent terdiri dari Harga (X1) dan kualitas pelayanan (X2). Sedangkan pada variabel dependent terdiri dari kepuasan (Y1) dan loyalitas (Y2).

Tabel 1. Identifikasi Variabel Penelitian

\begin{tabular}{clll}
\hline No & \multicolumn{1}{c}{ Variabel } & & \multicolumn{1}{c}{ Indikator } \\
\hline 1 & Harga (X1) (Kotler & 1. Keterjangkauan harga \\
& \& Amstrong, 2008) & 2. Kesesuaian harga dengan kualitas pelayanan \\
& & 3. Potongan harga khusus \\
& & 4. Kesesuaian harga dengan manfaat \\
\hline 2 & Kualitas Pelayanan & 1. Tangibels \\
& (X2) (Berry \& & 2. Reliability \\
& Parasuraman, 1985) & 3. Responsiveness \\
& & 4. Assurance \\
& & 5. Emphaty \\
\hline 3 & Kepuasan (Y1) & 1. Kesesuaian harapan \\
& Loyiptono, 2004) & 2. Keinginan melakukan transaksi lagi \\
& 3. Kesediaan merekomendasikan \\
\hline & & 1. Purchase across product and service lines \\
& & 2. Refers others \\
& & 3. Demonstrates in immunity to the pull of the \\
\end{tabular}

Jenis data yang digunakan dalam penelitian ini yaitu data kualitatif dan data kuantitatif. Adapun sumber data yang di dapat dalam penelitian ini, yaitu data primer dan data sekunder. Teknik dalam pengumpulan datapenelitian menggunakan tiga cara yaitu Observasi, kuesioner, dan dokumentasi. Responden dalam penelitian ini adalah Wisatawan Nusantara pengguna jasa penerbangan maskapai Lion Air di Bali. Adapun model dari J.Supranto yaitu mengalikan kelipatan 5 dengan jumlah pertanyaan atau indikator dalam kuesioner. Dalam pengambilan sampel pengguna, indikator dalam penelitian ini sebanyak 15, maka jumlah responden yang dijadikan sampel adalah 70 responden yang diperoleh dari mengalikan antara 5 dengan jumlah indikator dalam penelitian. Teknik analisis data yang digunakan adalah metode analisis kuantitatif yang dibantu menggunakan program SPSS16. Analisis kuantitatif yang digunakan dalam penelitian ini yaitu : Uji validitas dan reliabilitas instrumen, uji normalitas, dan uji analisis jalur (path analysis).

\section{HASIL DAN PEMBAHASAN}

Maraknya dunia penerbangan Indonesia saat ini boleh jadi dipelopori oleh munculnya 
maskapai penerbangan murah pertama di Indonesia, yaitu Lion Air. Dengan slogannya "We Make People Fly". Maskapai yang baru beroperasi awal tahun 2000-an tersebut memicu munculnya maskapai low cost lainnya. Bahkan kini, maskapai tersebut telah menduduki peringkat kedua sebagai maskapai dengan penumpang paling banyak di tanah air setelah Garuda Indonesia.Tahun 2013 PT. Lion Air mendirikan maskapai penerbangan jarak jauh bernama Batik Air. Maskapai tersebut menggunakan jenis pesawat Boeing 737-900ER. Batik Air didirikan untuk menampung penumpang kelas menengah keatas, sehingga harga tiket pesawat Batik Air relatif lebih mahal dibandingkan dengan pesawat Lion Air.

\section{Karakteristik Wisatawan Nusantara Pada Maskapai Lion Air di Bali}

Dalam penelitian ini, digolongkan beberapa indikator karakteristik wisatawan sebagai sampel penelitian diantaranya : jenis kelamin, pekerjaan, pendidikan, usia, dan pengeluaran. Karakteristik berdasarkan segi usia dapat diketahui bahwa usia Wisatawan Nusantara pada maskapai Lion Air di Bali didominasi oleh laki-laki sebanyak 45 atau $60 \%$ dari 70 sampel yang diambil untuk melakukan penelitian. Sementara perempuan berjumlah 30 atau $40 \%$. Karakteristik berdasarkan segi pekerjaan dapat diketahui bahwa pekerjaan Wisatawan Nusantara pada maskapai Lion Air di Bali sebagian besar adalah pengusaha sebanyak 40 orang $(53,3 \%)$ dan lain-lain yang terendah sebanyak 6 orang $(8,0 \%)$. Karakteristik berdasarkan segi pendidikan wisatawan nusantara pada maskapai Lion Air di Bali diperoleh yang tertinggi adalah berpendidikan sarjana sebanyak 38 orang $(50,7 \%)$ dan terendah berpendidikan SMU/Sederajat sebanyak 2 orang $(2,6 \%)$. Karakteristik berdasarkan usia Wisatawan Nusantara pada maskapai Lion Air di Bali sebagian besar responden yang berumur 46-55 tahun sebanyak 25 orang $(33,3 \%)$ dan terendah adalah 26- 35 tahun sebanyak 15 orang $(20 \%)$. Karakteristik berdasarkan segi pengeluaran Wisatawan Nusantara pada maskapai Lion Air di Bali karakteristik responden berdasarkan pengeluaran diperoleh sebagian besar berpengeluaran antara $\mathrm{Rp}$ 5.000 .001 - Rp 10.000.000 sebanyak 40 orang $(53,3 \%)$.

\section{Analisis Jalur (Path Analysis)}

Pengujian data pada penelitian ini menggunakan analisis jalur (path analysis) guna menguji pola hubungan yang mengungkapkan pengaruh variabel atau seperangkat variabel lainnya, baik pengaruh langsung maupun pengaruh tidak langsung. Untuk pendugaan parameter dilakukan dengan analisis regresi melalui software SPSS 17.0 for Windows diperoleh hasil sebaga

Substruktur 1:

$\mathrm{Y} 1=\beta_{1} \mathrm{X} 1+\beta_{2} \mathrm{X} 2+\varepsilon_{1}$ $\mathrm{Y} 1=0,344 \mathrm{X} 1+0,760 \mathrm{X} 2+\varepsilon_{1}$

Dari hasil perhitungan pada pengujian data diperoleh hasil pada Tabel 2.

Tabel 2. Coefficients Substruktur 1

\begin{tabular}{|c|c|c|c|c|c|c|}
\hline & \multirow{2}{*}{ Model } & \multicolumn{2}{|c|}{$\begin{array}{c}\text { Unstandardized } \\
\text { Coefficients }\end{array}$} & $\begin{array}{l}\text { Standardized } \\
\text { Coefficients }\end{array}$ & \multirow[b]{2}{*}{$\mathrm{t}$} & \multirow[b]{2}{*}{ Sig } \\
\hline & & B & td. Error & Beta & & \\
\hline \multirow[t]{3}{*}{1} & (Constant) & 3,179 & 0,479 & & 6,633 & 0,000 \\
\hline & $\mathrm{X} 1$ & 0,181 & 0,027 & 0,344 & 6,629 & 0,000 \\
\hline & $\mathrm{X} 2$ & 0,265 & 0,018 & 0,760 & 14,628 & 0,000 \\
\hline
\end{tabular}

Substruktur 2 :

$\mathrm{Y} 2=\beta_{1} \mathrm{X} 1+\beta_{2} \mathrm{X} 2+\beta_{3} \mathrm{Y} 1+\varepsilon_{2}$ $\mathrm{Y} 2=0,321 \mathrm{X} 1+0,764 \mathrm{X} 2+0,103 \mathrm{Y} 1+\varepsilon_{1}$
Dari hasil perhitungan pada pengujian data diperoleh hasil pada Tabel 3. 
Tabel 3. Coefficients Substruktur 1

\begin{tabular}{|c|c|c|c|c|c|}
\hline \multirow[t]{2}{*}{ Model } & \multicolumn{2}{|c|}{ Unstandardized Coefficients } & $\begin{array}{l}\text { Standardized } \\
\text { Coefficients }\end{array}$ & \multirow[b]{2}{*}{$\mathrm{t}$} & \multirow[b]{2}{*}{ Sig } \\
\hline & $\mathrm{B}$ & td. Error & Beta & & \\
\hline 1 (Constant) & 0,130 & 0,277 & & 0,469 & 0,640 \\
\hline $\mathrm{X} 1$ & 0,217 & 0,016 & 0,321 & 13,773 & 0,000 \\
\hline $\mathrm{X} 2$ & 0,342 & 0,016 & 0,764 & 20,870 & 0,000 \\
\hline Y1 & 0,133 & 0,054 & 0,103 & 2,479 & 0,016 \\
\hline
\end{tabular}

Correlations

Correlations

\begin{tabular}{llrrrr}
\hline & X1 & X2 & Y1 & Y2 \\
\hline X1 & Pearson Correlation & 1 & $.231^{*}$ & $.520^{* *}$ & $.551^{* *}$ \\
\cline { 2 - 6 } & Sig. (2-tailed) & & & & \\
\cline { 2 - 6 } & $\mathrm{N}$ & 75 & 75 & 75 & .000 \\
\hline $\mathrm{X} 2$ & Pearson Correlation & $.231^{*}$ & 1 & $.839^{* *}$ & $.925^{* *}$
\end{tabular}

\begin{tabular}{|c|c|c|c|c|}
\hline Sig. (2-tailed) & .046 & & .000 & .000 \\
\hline $\mathrm{N}$ & 75 & 75 & 75 & 75 \\
\hline Pearson Correlation & $.520^{* *}$ & $.839^{* *}$ & 1 & $.911^{* *}$ \\
\hline
\end{tabular}

\begin{tabular}{llrrrr}
\cline { 2 - 5 } & Sig. (2-tailed) & .000 & .000 & & .000 \\
\cline { 2 - 5 } & $\mathrm{N}$ & 75 & 75 & 75 & 75 \\
\hline Y2 & Pearson Correlation & $.551^{* *}$ & $.925^{* *}$ & $.911^{* *}$ & 1
\end{tabular}

\begin{tabular}{lrrrr}
\hline Sig. (2-tailed) & .000 & .000 & .000 & \\
\hline $\mathrm{N}$ & 75 & 75 & 75 & 75 \\
\hline
\end{tabular}

*. Correlation is significant at the 0.05 level (2-tailed).

**Correlation is significant at the 0.01 level (2-tailed).

Berdasarkan perhitungan terhadap substruktur 1, dan 2, maka dapat diketahui besarnya pengaruh langsung, pengaruh tidak langsung dan pengaruh total antar variabel. Perhitungan pengaruh antar variabel adalah sebagai berikut.

1. Pengaruh Langsung (Direct Effect)

Besarnya pengaruh variabel harga dan kualitas pelayanan terhadap kepuasan, serta kepuasan terhadap loyalitas dilihat dari nilai beta atau Standardized Coefficient adalah sebagai berikut.

a) Pengaruh variabel harga terhadap kepuasan

$\mathrm{X}_{1} \longrightarrow \mathrm{Y}_{1}=0,344 \times 0,344=0,118$ b) Pengaruh variabel kualitas pelayanan terhadap kepuasan

$\mathrm{X}_{2} \longrightarrow \mathrm{Y}_{1}=0,760 \times 0,760=0,577$

c) Pengaruh variabel kepuasan terhadap loyalitas

$\mathrm{Y}_{1} \longrightarrow \mathrm{Y}_{2}=0,103 \times 0,103=0,01$

d) Pengaruh variabel harga terhadap loyalitas

$\mathrm{X}_{1} \longrightarrow \mathrm{Y}_{2}=0,321 \times 0,321=0,103$

e) Pengaruh variabel kualitas pelayanan terhadap loyalitas

$\mathrm{X}_{2} \longrightarrow \mathrm{Y}_{2}=0,764 \times 0,764=0,583$

2. Pengaruh Tidak Langsung (Indirect Effect)

a) Pengaruh variabel harga terhadap loyalitas melalui kepuasan. 


$$
\begin{aligned}
& \mathrm{X} 1 \rightarrow \mathrm{Y} 1 \rightarrow \mathrm{Y} 2=(0,344 \times 0,103 \times \\
& 0,551)=0,02
\end{aligned}
$$

b) Pengaruh variabel kualitas pelayanan terhadap loyalitas melalui kepuasan. $\mathrm{X} 2 \rightarrow \mathrm{Y} 1 \rightarrow \mathrm{Y} 2=(0,760 \times 0,103 \mathrm{x}$ $0,925)=0,07$

3. Pengaruh Total (Total Effect)

Pengaruh total $=$ pengaruh langsung + pengaruh tidak langsung

$=0,118+0,577+0,01+0,103+0,583+$ $0,02+0,07$

$=1,481$

Persamaan struktural untuk model penelitian ini adalah :

- Substruktur 1:

$$
\begin{aligned}
& \mathrm{Y} 1=\beta_{1} \mathrm{X} 1+\beta_{2} \mathrm{X} 2+\varepsilon_{1} \\
& \mathrm{Y} 1=0,344 \mathrm{X} 1+0,760 \mathrm{X} 2+\mathrm{e} \\
& \text { Pengaruh error }(\mathrm{Pei})=\sqrt{ } 1-\mathrm{R}^{2} \\
& \mathrm{Pei}=\sqrt{ } 1-0,816=\sqrt{ } 0,18=0,43
\end{aligned}
$$

- Substruktur 2:

$$
\begin{aligned}
& \mathrm{Y} 2=\beta_{1} \mathrm{X} 1+\beta_{2} \mathrm{X} 2+\beta_{3} \mathrm{Y} 1+\varepsilon_{2} \\
& \mathrm{Y}_{2}=0,321 \mathrm{X} 1+0,764 \mathrm{X} 2+0,103 \mathrm{Y}_{1}+\mathrm{e} \\
& \text { Pengaruh error }(\mathrm{Pei})=\sqrt{ } 1-\mathrm{R}^{2} \\
& \text { Pei }=\sqrt{ } 1-0,977=\sqrt{ } 0,023=0,15
\end{aligned}
$$

4. Pemeriksaan Validasi Model

Ada dua indikator untuk melakukan pemeriksaan validitas model, yaitu koefisien determinasi total dan theory triming dimana hasilnya dapat disajikan sebagai berikut.

1) Hasil koefisien determinasi total :

$\mathrm{R}_{\mathrm{m}}^{2}=1-(1-0,816)(1-0,977)$

$\mathrm{R}_{\mathrm{m}}^{2}=1-0,004$

$\mathrm{R}_{\mathrm{m}}^{2}=0,995$

Artinya, keragaman data yang dapat dijelaskan oleh model adalah sebesar 99,5 persen atau dengan kata lain informasi yang terkandung dalam data sebesar 99,5 persen dapat dijelaskan oleh model, sedangkan sisanya yaitu 0,5 persen dijelaskan oleh variabel lain (tidak terdapat dalam model) dan error.

2) Theory Triming

Pendekatan ini dilakukan dengan membuang jalur-jalur yang non signifikan agar memperoleh model yang benar-benar didukung oleh data empirik. Uji validasi pada setiap jalur untuk pengaruh langsung adalah sama dengan regresi, menggunakan nilai $\mathrm{p}$ dari uji $\mathrm{t}$ yaitu pengujian koefisien regresi variabel dibakukan secara parsial dengan nilai X1 terhadap Y1 adalah 6,629 sig 0,00, nilai $\mathrm{X} 2$ terhadap $\mathrm{Y} 1$ adalah 14,628 sig 0,00 , Y1 terhadap Y2 sebesar 2,479 sig 0,016.

\section{Pengaruh Harga Terhadap Kepuasan Wisatawan Nusantara}

Berdasarkan hasil perhitungan diperoleh taraf signifikansi penelitian untuk variabel harga terhadap kepuasan sebesar $0,000<0,05$, sehingga $\mathrm{H} 0$ ditolak dan $\mathrm{H} 1$ diterima, dengan kata lain harga berpengaruh positif dan signifikan terhadap kepuasan Wisatawan Nusantara pada maskapai lion air di Bali.

Harga (price) memiliki pengaruh terhadap kepuasan wisatawan dalam pembelian sebuah produk. Hasil penelitian ini mendukung penelitian yang dilakukan oleh Alfi Sukma Wijaya (2014) menyatakan bahwa harga berpengaruh positif dan signifikan terhadap kepuasan pelanggan. Kemudian penelitian yang dilakukan oleh Lukman Khakim (2012) menyatakan bahwa harga berpengaruh positif dan signifikan terhadap kepuasan pelanggan.

\section{Pengaruh Kualitas Pelayanan Terhadap Kepuasan Wisatawan Nusantara}

Berdasarkan hasil perhitungan diperoleh taraf signifikansi penelitian untuk variabel kualitas pelayanan terhadap kepuasan sebesar $0,000<0,05$, sehingga $\mathrm{H} 0$ ditolak dan $\mathrm{H} 1$ diterima, dengan kata lain kualitas pelayanan berpengaruh positif dan signifikan terhadap kepuasan Wisatawan Nusantara pada maskapai lion air di Bali.

Hasil penelitian ini mendukung penelitian yang dilakukan oleh Andri Tiyono (2012) menyatakan bahwa kualitas pelayanan berpengaruh positif dan signifikan terhadap kepuasan pelanggan jasa penerbangan Express Airline.

\section{Pengaruh Kepuasan Terhadap Loyalitas Wisatawan Nusantara}

Berdasarkan hasil perhitungan diperoleh taraf signifikansi penelitian untuk variabel kepuasan terhadap loyalitas sebesar 0,016 < 0,05, sehingga H0 ditolak dan $\mathrm{H} 1$ diterima, dengan kata lain kepuasan berpengaruh positif dan signifikan terhadap loyalitas Wisatawan Nusantara pada maskapai Lion Air di Bali. 
Hasil penelitian ini juga sesuai dengan yang dilakukan Robertus (2011) menyatakan bahwa kepuasan berpengaruh langsung terhadap loyalitas konsumen minyak goreng Bimoli di Wilayah Perumnas Krapyak. Yang berarti kepuasan berpengaruh positif dan signifikan terhadap loyalitas pelanggan.

\section{Pengaruh Harga Terhadap Loyalitas Wisatawan Nusantara}

Berdasarkan hasil perhitungan diperoleh taraf signifikansi penelitian untuk variabel harga terhadap loyalitas sebesar $0,000<0,05$, sehingga $\mathrm{H} 0$ ditolak dan $\mathrm{H} 1$ diterima, dengan kata lain harga berpengaruh positif dan signifikan terhadap loyalitas Wisatawan Nusantara pada maskapai Lion Air di Bali.

Penelitian ini juga didukung oleh penelitian sebelumnya yang dilakukan oleh Nurhayati (2011) menyatakan bahwa terdapat pengaruh positif dan signifikan antara harga dengan loyalitas pelanggan

\section{Pengaruh Kualitas Pelayanan Terhadap Loyalitas Wisatawan Nusantara}

Berdasarkan hasil perhitungan diperoleh taraf signifikansi penelitian untuk variabel kepuasan terhadap loyalitas sebesar $0,000<$ 0,05 , sehingga $\mathrm{H} 0$ ditolak dan $\mathrm{H} 1$ diterima, dengan kata lain kualitas pelayanan berpengaruh positif dan signifikan terhadap loyalitas wisatawan nusantara pada maskapai Lion Air di Bali.

Hasil penelitian ini juga sesuai dengan penelitian yang dilakukan oleh Rifky (2015) menyatakan bahwa terdapat pengaruh positif dan signifikan antara kualitas pelayanan terhadap loyalitas pelanggan.

\section{SIMPULAN DAN SARAN}

\section{Simpulan}

1. Harga berpengaruh positif dan signifikan terhadap kepuasan Wisatawan Nusantara pada maskapai Lion Air di Bali. Harga yang rendah membuat pengguna jasa Lion Air khususnya Wisatawan Nusantara menjadi puas.

2. Kualitas pelayanan berpengaruh positif dan signifikan terhadap kepuasan wisatawan nusantara pada maskapai Lion Air di Bali. Semakin baik kualitas pelayanan maka wisatawan yang menggunakan jasa Lion Air semakin puas.

3. Kepuasan secara simultan berpengaruh positif dan signifikan terhadap loyalitas wisatawan nusantara pada maskapai Lion Air di Bali. Harga yang rendah dan tidak mengurangi kualitas pelayanan yang baik maka wisatawan menjadi puas dan akan loyal terhadap maskapai Lion Air.

4. Harga berpengaruh positif dan signifikan terhadap loyalitas wisatawan nusantara pada maskapai Lion Air di Bali. Semakin menurun harga tiket yang ditawarkan maka wisatawan yang menggunakan jasa Lion Air semakin Loyal.

5. Kualitas pelayanan berpengaruh positif dan signifikan terhadap loyalitas wisatawan nusantara pada maskapai Lion Air di Bali. Semakin baik kualitas pelayanan yang diberikan kepada wisatawan pengguna jasa Lion Air, maka wisatawan akan loyal.

\section{Saran}

Berdasarkan hasil penelitian yang telah dilakukan, kualitas pelayanan mempunyai tingkat pengaruh yang lebih besar dari harga dan kepuasan, maka saran kepada pihak Lion Air agar pihak Lion Air bisa lebih lagi memberikan kualitas pelayanan yang terbaik, terutama pelayanan jam penerbangan agar tidak sering terjadi delay dan wisatawan semakin loyal.

\section{DAFTAR PUSTAKA}

Alfi. 2014. Pengaruh harga, kualitas produk dan kualitas pelayanan terhadap loyalitas pelanggan melalui kepuasan pelanggan pada counter HP Jati Bird Semarang.

Badan Pusat Statistik. Jumlah Kunjungan Wisatawan Nusantara dan Mancanegara ke Bali tahun 20102015.

http://bali.bps.go.id/table_detail.php?e $\mathrm{d}=604001 \&$ od $=4 \& \mathrm{id}=4$ (Di unduh pada tanggal 24 mei 2016).

Dinas Pariwisata Provinsi Bali. 2015. “Jumlah Kunjungan Wisatawan ke Bali 2010 2015 ". 
Jurnal IPTA

ISSN : 2338-8633

Vol. 4 No. 2, 2016

http://www.disparda.baliprov.go.id/id/Stat istik2 (Di unduh tanggal 24 mei 2016).

International Air Transport. 1998. "Air Tarif". Sweden : IATA.

Rifky. 2015. Pengaruh Tarif Kamar dan Kualitas Pelayanan Terhadap Loyalitas Pelanggan melalui Kepuasan Pelanggan pada Horison Hotel Semarang. 